\title{
Aroylation of 2- and 3-acetylthiophenes using benzoyl chloride, benzotrichloride, and their substituted derivatives
}

\author{
Leonid I. Belen'kii,* Galina P. Gromova, Anton V. Kolotaev, and Sergei I. Luiksaar
}

N. D. Zelinsky Institute of Organic Chemistry, Russian Academy of Sciences, Leninsky Prospect, 47, 119991 Moscow, Russia

E-mail: libel@cacr.ioc.ac.ru

\begin{abstract}
Dedicated to Professor Mikhail G. Voronkov on the occasion of his $80^{\text {th }}$ birthday
\end{abstract} (received 01 Jun 01; accepted 08 Jan 02; published on the web 16 Jan 02)

\begin{abstract}
Aryldichlorocarbenium tetrachloroaluminates are shown to be preferable reagents for the aroylation of 2-acetylthiophene, while the usual $\mathrm{ArCOCl} \cdot \mathrm{AlCl}_{3}$ complexes give better results in aroylation of 3-acetylthiophene. Scope and limitations of both aroylation procedures are discussed.
\end{abstract}

Keywords: Aryldichlorocarbenium tetrachloroaluminates, complexes of aroyl chlorides with $\mathrm{AlCl}_{3}, 2$-acetylthiophene, 3-acetylthiophene, aroylation

\section{Introduction}

Previously, the effect of complex formation with Lewis and Brønsted acids on the reactivity of carbonyl compounds of thiophene derivatives and, especially, on the orientation of the electrophilic attack at the thiophene ring has been studied by our group extensively (see reviews $^{1,2}$ ). It has been shown that in such complexes the reactivity of carbonyl compounds is suppressed and the orientation is changed: electrophiles do not enter the free $\alpha$ '-position as usual, but preferentially or even exclusively attack position 4 that upon complex formation is deactivated to the lesser extent. In particular, 2-acylthiophenes are acylated with acetyl and chloroacetyl chlorides in the presence of excess anhydrous aluminum chloride without a solvent at ca $100{ }^{\circ} \mathrm{C}$ affording 2,4-diacylthiophenes with an admixture (6-8\%) of the 2,5-isomer in 50$70 \%$ total yield with respect to the consumed ketone. ${ }^{3,4}$ The reaction of 2-acetylthiophene (1) with benzoyl chloride under the conditions mentioned is complicated by transacylation, and therefore, results in a mixture of products containing 2-benzoylthiophene (yield ca 30\%) as well as diacetyl-, acetylbenzoyl- (13\% of the total products) and dibenzoylthiophenes (Scheme 1). ${ }^{4}$ 


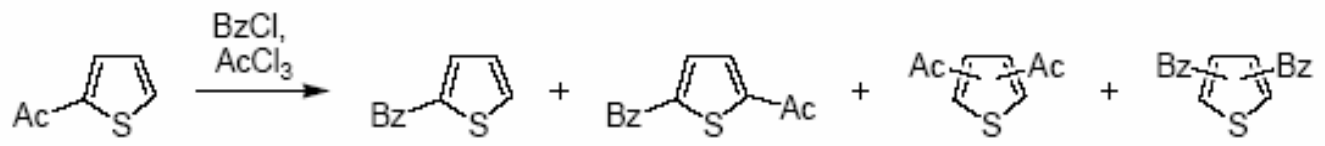

\section{Scheme 1}

Acylation of 3-acylthiophenes with acyl chlorides proceeds more smoothly affording the corresponding 2,4-diacylthiophenes in 70-80\% yields without 2,5-isomer. ${ }^{4}$

Recently, we have shown that the undesirable transacylation reaction accompanying the benzoylation of 2-acylthiophenes can be suppressed by replacing the $\mathrm{PhCOCl} \cdot \mathrm{AlCl}_{3}$ complex by phenyldichlorocarbenium tetrachloroaluminate $\left[\mathrm{PhCCl}_{2}\right]^{+} \mathrm{AlCl}_{4}{ }^{-}$; actually, this complex is an alkylating and not an acylating agent: the corresponding substituted arylhetaryldichloromethanes are the primary products. ${ }^{5}$ Thus, 2-acetylthiophene (1) and benzotrichloride with an excess of aluminum chloride (to form $\mathbf{1} \cdot \mathrm{AlCl}_{3}$ and $\left[\mathrm{PhCCl}_{2}\right]^{+}\left[\mathrm{AlCl}_{4}\right]^{-}$complexes) gave, at a reaction temperature of ca. $80^{\circ} \mathrm{C}$ and after treatment of the reaction mixture with an acidic, aqueous alcohol solution, 2-acetyl-4-benzoylthiophene (2a) without admixture of the 2,5-isomer (as indicated by ${ }^{1} \mathrm{H}$ NMR; Scheme 2 ). ${ }^{5}$

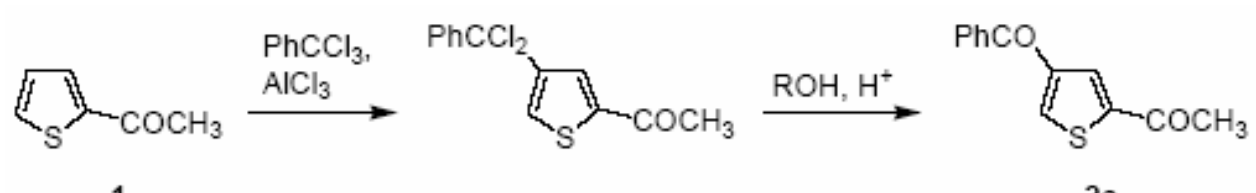

1

$2 a$

\section{Scheme 2}

The goal of the present work was the comparison of trichloromethylarenes and aroyl chlorides in the preparation of 2,4-diacylthiophenes. As starting materials for the generation of the aryldichlorocarbenium tetrachloroaluminates both benzotrichloride and some substituted benzotrichloride derivatives were employed; substituted benzoyl chlorides were used as well. 2Acetylthiophene (1) and 3-acetylthiophene (3) were the substrates selected for studying the scope and the limitations of reactions mentioned.

\section{Results and Discussion}

Taking into account the side reactions encountered by using benzoyl chloride with $\mathrm{AlCl}_{3}$ in the benzoylation of 2-acetylthiophene (1), ${ }^{4}$ aryldichlorocarbenium tetrachloro-aluminates can be suggested as the preferable reagents for the aroylation of 1. Particularly, we have shown ${ }^{5}$ that in the presence of aluminum chloride, benzotrichloride reacts with 2-acetylthiophene selectively and at lower temperature than benzoyl chloride to give diketone $2 \mathbf{a}$ in a much higher yield $\left(50 \%{ }^{5}\right.$ instead of $13 \%^{4}$ ). 


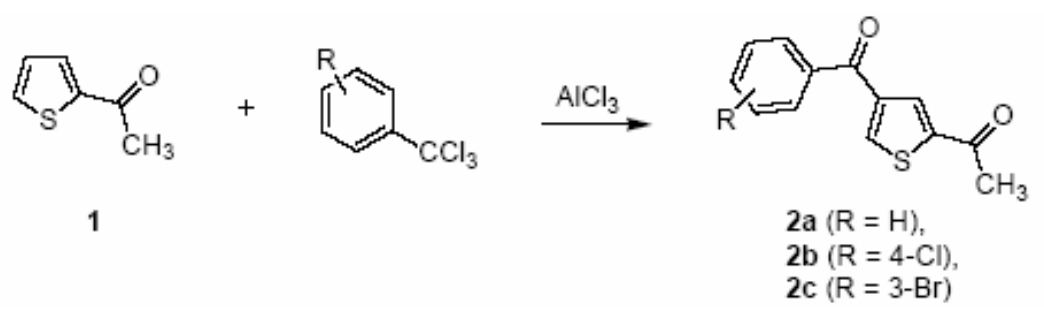

\section{Scheme 3}

In this work, 2-acetylthiophene (1) is shown to react with 4-chlorobenzotrichloride at 70-85 ${ }^{\circ} \mathrm{C}$ giving 2-acetyl-4-(4-chlorobenzoyl)thiophene (2b) in 39\% yield. With 3-bromobenzotrichloride at $95-100{ }^{\circ} \mathrm{C}$, the yield of 2-acetyl-4-(3-bromobenzoyl)thiophene (2c) is $32 \%$ (Scheme 3). Our attempts to carry out similar acylation reactions using 2,4-dimethyl- and 2chlorobenzotrichlorides failed. Polymer formation took place, and part of the starting compounds was recovered, probably due to steric hindrance of the $\mathrm{ArCCl}^{2+}$ group and an ortho substituent.

Unexpectedly, the yield of 4-acetyl-2-benzoylthiophene (4a) from the reaction of benzotrichloride and 3-acetylthiophene (3) was lower than described ${ }^{4}$ for the reaction with benzoyl chloride ( $47 \%$ as compared to $76 \%$ ). Considering the yields mentioned and the evidence, that the employment of acid chlorides does not require an additional hydrolysis step of the resulting arylhetaryldichloromethanes, there is no obvious advantage of using substituted benzotrichlorides in aroylation reactions of 3-acetylthiophene (3). Reactions of the latter with substituted benzoyl chlorides proceeded more smoothly than in the case of 2-acetylthiophene (1) and give 4-acetyl-2-aroylthiophenes $(\mathbf{4 b}, \mathbf{c})$ in rather high yields. Thus, 3 -acetylthiophene reacted with 3-bromobenzoyl chloride at $98-100{ }^{\circ} \mathrm{C}$ and with 4-fluoro-benzoyl chloride at $80-90{ }^{\circ} \mathrm{C}$ affording 4-acetyl-2-(3-bromobenzoyl)thiophene (4b) and 4-acetyl-2-(4-fluorobenzoyl)thiophene (4c) in $65 \%$ and $46 \%$ yields, respectively (Scheme 4 ).

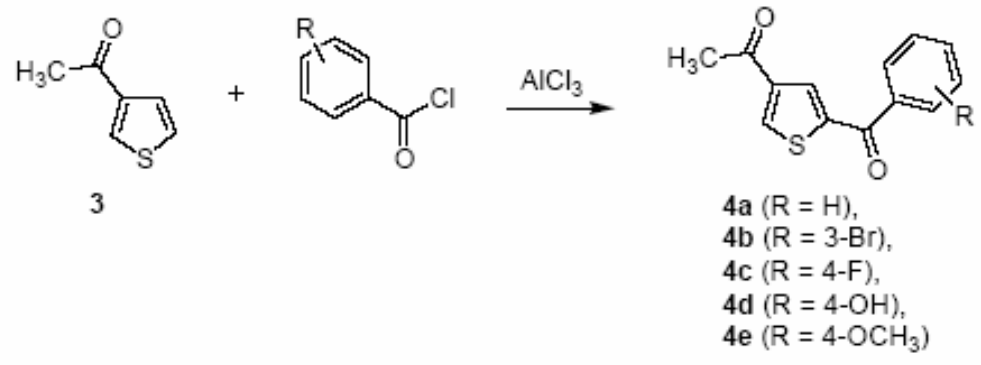

\section{Scheme 4}

However, not all tested aroyl chlorides were sufficiently stable under the acylation conditions applied. Thus, we could not obtain any product from the reaction with 4-(trifluoromethyl)benzoyl chloride. In the case of 4-methoxybenzoyl chloride the main product was the demethylated 4-acetyl-2-(4-hydroxybenzoyl)thiophene (4d). 4-Acetyl-2-(4methoxybenzoyl)thiophene (4e) could be obtained in low yield (15\%) only after methylation with dimethyl sulfate of the primarily formed reaction mixture of $\mathbf{4 d}$ and $\mathbf{4 e}$ (Scheme 4).

In summary, aryldichlorocarbenium tetrachloroaluminates have been shown to be preferable 
reagents for the aroylation of 2-acetylthiophene, whereas the usual $\mathrm{ArCOCl} \cdot \mathrm{AlCl}_{3}$ complexes give better results in aroylation of 3 -acetylthiophene.

\section{Experimental Section}

General Procedures. ${ }^{1} \mathrm{H}$ NMR spectra of $\mathrm{CDCl}_{3}$ solutions were recorded with a Bruker AC-200 instrument $(200 \mathrm{MHz})$.

The purity of the products was checked by TLC on Silufol UV-254 using petroleum ether/ethyl acetate mixtures (3:1 for $\mathbf{2 b}, 2: 1$ for $\mathbf{4 e}, 5: 1$ in all other cases) as eluents. Light petroleum ether refers to the fraction of boiling range $40-60{ }^{\circ} \mathrm{C}$, petroleum ether refers to the fraction of boiling range $60-80^{\circ} \mathrm{C}$. All starting materials, ketones, benzotrichloride, and the aroyl chlorides, were commercially available reagents (Aldrich, Merck). 2,4-Dimethylbenzotrichloride was prepared by trichloromethylation of $m$-xylene; ${ }^{6}$ 3-bromobenzotrichloride was obtained from 3-bromobenzotrifluoride with $\mathrm{AlCl}_{3}$ and $\mathrm{AcCl}$ according to a known procedure; ${ }^{7}$ 2chlorobenzotrichloride and 4-chlorobenzotrichloride were prepared by side-chain chlorination of 2- and 4-chlorotoluene, respectively, following literature procedures. ${ }^{8}$

2-Acetyl-4-(4-chlorobenzoyl)thiophene (2b). To the mixture of $\mathbf{1}$ (5 g, $4.3 \mathrm{~mL}, 39.7 \mathrm{mmol})$ and $\mathrm{AlCl}_{3}(15.88 \mathrm{~g}, 119.0 \mathrm{mmol})$ was added dropwise with stirring 4-chlorobenzotrichloride $(9.13 \mathrm{~g}$, $6.1 \mathrm{~mL}, 39.7 \mathrm{mmol})$. The mixture was stirred at $70-85{ }^{\circ} \mathrm{C}$ for $15 \mathrm{~min}$ until the evolution of hydrogen chloride ceased, and after cooling it was poured onto ice. The aqueous layer was extracted with chloroform, the extract was washed with water until neutral, dried over $\mathrm{MgSO}_{4}$, and the solvent was evaporated. The residue, a dark brown liquid (13.15 g), was dissolved in ethanol $(50 \mathrm{~mL})$ containing $\mathrm{H}_{2} \mathrm{SO}_{4}(0.5 \mathrm{~mL})$, and the solution was refluxed for $3.5 \mathrm{~h}$. After cooling the solution, the crude semisolid precipitate $(5.34 \mathrm{~g})$ was filtered off. The filtrate was partially evaporated, diluted with chloroform, and the resulting solution was washed with water, then with an aqueous solution of $\mathrm{Na}_{2} \mathrm{CO}_{3}$ followed by water, and dried over $\mathrm{MgSO}_{4}$. Upon evaporation of the solvent the residual oil (4.95 g) was boiled with petroleum ether and gave after recrystallization from light petroleum ether colorless crystals of the diketone $\mathbf{2 b}(4.09 \mathrm{~g}$, 39\%); mp 126-127 ${ }^{\circ} \mathrm{C} .{ }^{1} \mathrm{H}$ NMR: $\delta 2.62(3 \mathrm{H}, \mathrm{s}, \mathrm{Me}), 7.50(2 \mathrm{H}, \mathrm{m}, \mathrm{m}-\mathrm{H}), 8.10$ and $7.76(2 \mathrm{H}, \mathrm{m}$, $o-\mathrm{H}), 7.84(1 \mathrm{H}, \mathrm{d}, 3-\mathrm{H}), 8.13(1 \mathrm{H}, \mathrm{d}, 5-\mathrm{H})$. Anal. Calcd. for $\mathrm{C}_{13} \mathrm{H}_{9} \mathrm{ClO}_{2} \mathrm{~S}: \mathrm{C}, 58.98 ; \mathrm{H}, 3.43 ; \mathrm{Cl}$, 13.39; S 12.11. Found: C, 58.93; H, 3.59; Cl, 13.12; S, 11.86.

2-Acetyl-4-(3-bromobenzoyl)thiophene (2c). $\mathrm{To}^{\mathrm{AlCl}_{3}}$ (16 g, $120 \mathrm{mmol}$ ) was added in portions while cooling with cold water 1 (5 g, $40 \mathrm{mmol}$ ). To the liquid complex formed, 3bromobenzotrichloride $(10.9 \mathrm{~g}, 40 \mathrm{mmol})$ was added dropwise with stirring. The reaction mixture was heated at $95-100{ }^{\circ} \mathrm{C}$ for $20 \mathrm{~min}$ and worked-up as described before. After evaporation of chloroform extract the oily residue was dissolved in $i-\mathrm{PrOH}(100 \mathrm{~mL})$; conc. $\mathrm{H}_{2} \mathrm{SO}_{4}(0.5 \mathrm{~mL})$ was added, and the solution was refluxed for $1 \mathrm{~h}$. The hot solution was decanted from a resinous lower layer. Upon cooling the solution, the separated diketone crystals were 
filtered off and washed with cold $i$-PrOH affording colorless crystals 2c (5.2 g, 35\%); mp 152$153{ }^{\circ} \mathrm{C}(\mathrm{i}-\mathrm{PrOH}) .{ }^{1} \mathrm{H}$ NMR: $\delta 2.63(3 \mathrm{H}, \mathrm{s}, \mathrm{Me}), 7.41(1 \mathrm{H}, \mathrm{m}, \mathrm{m}-\mathrm{H}), 7.74(1 \mathrm{H}, \mathrm{m}, p-\mathrm{H}), 7.77$ and $8.12(2 \mathrm{H}, \mathrm{m}, o-\mathrm{H}), 7.97(1 \mathrm{H}, \mathrm{d}, 3-\mathrm{H}), 8.17(1 \mathrm{H}, \mathrm{d}, 5-\mathrm{H})$. Anal. Calcd. for $\mathrm{C}_{13} \mathrm{H}_{9} \mathrm{BrO}_{2} \mathrm{~S}: \mathrm{C}, 50.50$; H, 2.93; Br, 25.84; S, 10.37. Found: C, 50.57; H, 2.99; Br, 24.42; S, 9.80.

4-Acetyl-2-benzoylthiophene (4a). $\mathrm{To} \mathrm{AlCl}_{3}(23.7 \mathrm{~g}, 178 \mathrm{mmol})$ was added 3 (7.5 g, $\left.59 \mathrm{mmol}\right)$. Upon addition of benzotrichloride $(11.6 \mathrm{~g}, 8.4 \mathrm{~mL}, 59 \mathrm{mmol})$ the temperature of the mixture rose to $47{ }^{\circ} \mathrm{C}$, and subsequently, the reaction temperature was maintained in the range $90-93{ }^{\circ} \mathrm{C}$ for $30 \mathrm{~min}$. After the $\mathrm{HCl}$ evolution has ceased, the reaction mixture was cooled, chloroform (60 $\mathrm{mL}$ ) was added, and the mixture was poured onto ice. The organic layer was separated, and the aqueous layer was extracted with chloroform. The combined extracts were evaporated, dissolved in ethanol $(90 \mathrm{~mL})$, and after addition of $\mathrm{H}_{2} \mathrm{SO}_{4}(1.5 \mathrm{~mL})$ the solution was refluxed for $2 \mathrm{~h}$. The treatment of the ethanolic solution as described above gave diketone 4a $(6.41 \mathrm{~g}, 47 \%)$ as colorless crystals; mp 92-93 ${ }^{\circ} \mathrm{C}$ (lit. $\left.{ }^{4} 92-93{ }^{\circ} \mathrm{C}\right) .{ }^{1} \mathrm{H}$ NMR: $\delta 2.56(3 \mathrm{H}, \mathrm{s}, \mathrm{Me}), 7.51$ (2H, m, mH), $7.62(1 \mathrm{H}, \mathrm{m}, p-\mathrm{H}), 7.83(2 \mathrm{H}, \mathrm{m}, o-\mathrm{H}), 8.01(1 \mathrm{H}, \mathrm{d}, 3-\mathrm{H}), 8.37(1 \mathrm{H}, \mathrm{d}, 5-\mathrm{H})$.

4-Acetyl-2-(3-bromobenzoyl)thiophene (4b). To the stirred mixture of $3(2.0 \mathrm{~g}, 15.8 \mathrm{mmol})$ and $\mathrm{AlCl}_{3}$ (6.32 g, $\left.47.4 \mathrm{mmol}\right), 3$-bromobenzoyl chloride $(2.1 \mathrm{~mL}, 3.47 \mathrm{~g}, 15.8 \mathrm{mmol}$ ) was added. The evolution of hydrogen chloride started at $57{ }^{\circ} \mathrm{C}$, and at $72{ }^{\circ} \mathrm{C}$ the temperature rose to $98{ }^{\circ} \mathrm{C}$ with concomitant vigorous $\mathrm{HCl}$ evolution. The reaction at $98-100{ }^{\circ} \mathrm{C}$ was completed within $12 \mathrm{~min}$. After the $\mathrm{HCl}$ evolution had ceased, the reaction mixture was cooled, chloroform $(20 \mathrm{~mL})$ was added, and the mixture was poured onto ice. The organic layer was separated, and the aqueous layer was extracted with chloroform. The combined extracts were dried over $\mathrm{MgSO}_{4}$, the solvent was evaporated, and a crude product $(5 \mathrm{~g})$ was obtained. Recrystallization from ethanol gave colorless crystals of diketone $4 \mathbf{b}(3.2 \mathrm{~g}, 65 \%)$; mp 101-102 ${ }^{\circ} \mathrm{C}$. An analytical sample 4b was prepared, mp 103-105 ${ }^{\circ} \mathrm{C}$ (ethanol). ${ }^{1} \mathrm{H}$ NMR: $\delta 2.56(3 \mathrm{H}, \mathrm{s}, \mathrm{Me}), 7.40(1 \mathrm{H}, \mathrm{m}$, $m-\mathrm{H}), 7.77(2 \mathrm{H}, \mathrm{m}, p-\mathrm{H}$ and $o-\mathrm{H}), 7.99(1 \mathrm{H}, \mathrm{m}, o-\mathrm{H}), 7.99(1 \mathrm{H}, \mathrm{d}, 3-\mathrm{H}), 8.36(1 \mathrm{H}, \mathrm{d}, 5-\mathrm{H})$. Anal. Calcd. for $\mathrm{C}_{13} \mathrm{H}_{9} \mathrm{BrO}_{2} \mathrm{~S}: \mathrm{C}, 50.50 ; \mathrm{H}, 2.93 ; \mathrm{Br}, 25.84 ; \mathrm{S}, 10.37$. Found: C, 50.51; H, 3.05; Br, 25.25; S, 10.13.

4-Acetyl-2-(4-fluorobenzoyl)thiophene (4c). To $\mathrm{AlCl}_{3}(9.6 \mathrm{~g}, 72 \mathrm{mmol}), 3$ (3.0 g, $\left.24 \mathrm{mmol}\right)$ was added in portions. Upon stirring and cooling a liquid complex was formed. The cooling water bath was removed, and 4-fluorobenzoyl chloride $(2.83 \mathrm{~mL}, 3.81 \mathrm{~g}, 24 \mathrm{mmol})$ was added dropwise. Heating the mixture to $40{ }^{\circ} \mathrm{C}$ induced the evolution of $\mathrm{HCl}$. The reaction was carried out for $35 \mathrm{~min}$ at $80-90{ }^{\circ} \mathrm{C}$. After removal of the heating bath, the mixture became viscous. Dichloromethane $(50 \mathrm{~mL})$ was added, and the resulting solution was poured onto ice. The organic layer was separated, washed with water several times until neutral, and dried over $\mathrm{CaCl}_{2}$. The solvent was evaporated, and the crystalline residue was recrystallized from light petroleum ether affording colorless crystals of diketone $4 \mathrm{c}(4.3 \mathrm{~g}, 46 \%)$; mp $114-115^{\circ} \mathrm{C} .{ }^{1} \mathrm{H} \mathrm{NMR}$ : $\delta 2.55$ $(3 \mathrm{H}, \mathrm{s}, \mathrm{Me}), 7.22(2 \mathrm{H}, \mathrm{m}, \mathrm{m}-\mathrm{H}), 7.91(2 \mathrm{H}, \mathrm{m}, \mathrm{o}-\mathrm{H}), 8.00(1 \mathrm{H}, \mathrm{d}, 3-\mathrm{H}), 8.35(1 \mathrm{H}, \mathrm{d}, 5-\mathrm{H})$. Anal. Calcd. for $\mathrm{C}_{13} \mathrm{H}_{9} \mathrm{FO}_{2} \mathrm{~S}$ : C, 62.89; H, 3.65. Found: C, 62.91; H. 3.66.

Reaction of 3-acetylthiophene (3) with 4-methoxybenzoyl chloride. To the complex obtained from $\mathrm{AlCl}_{3}(4.74 \mathrm{~g}, 35.6 \mathrm{mmol})$ and $3(1.0 \mathrm{~g}, 7.9 \mathrm{mmol})$, 4-methoxybenzoyl chloride (1.755 g, 
$10.3 \mathrm{mmol}$ ) was added in portions at $56-78{ }^{\circ} \mathrm{C}$ within $25 \mathrm{~min}$. A vigorous $\mathrm{HCl}$ evolution took place, and the mixture solidified. Dichloromethane $(20 \mathrm{~mL})$ was added to the mixture, and the resulting solution was treated with water. The organic layer was washed with water and dried over $\mathrm{MgSO}_{4}$. After removal of the solvent, a mixture $(2 \mathrm{~g})$ was obtained, containing $3\left({ }^{1} \mathrm{H} \mathrm{NMR}\right.$ and TLC), 3-acetyl-5-(4-hydroxybenzoyl)thiophene (4d), and 3-acetyl-5-(4methoxybenzoyl)thiophene (4e). The mixture was refluxed in a solution of $\mathrm{NaOH}(0.35 \mathrm{~g}, 8.7$ $\mathrm{mmol})$ in water $(3.5 \mathrm{~mL})$ together with $\mathrm{Me}_{2} \mathrm{SO}_{4}(0.554 \mathrm{~g}, 4.4 \mathrm{mmol})$ for $3 \mathrm{~h}$. The reaction mixture was extracted with ether, and after removal of the solvent, the product was obtained as viscous oil (1.0 g). Column chromatography (silica gel, petroleum ether/ethyl acetate 5:1 $\rightarrow$ 2:1 as eluent) gave three fractions: Fraction 1 contained starting material $3(0.31 \mathrm{~g})$; fraction $2(0.48$ g) was a mixture of the methoxy-substituted diketone $4 \mathbf{e}$ with the hydroxy-substituted diketone 4d; fraction 3 was mainly the hydroxy-substituted diketone $4 \mathbf{d}(0.12 \mathrm{~g})$.

4-Acetyl-2-(4-methoxybenzoyl)thiophene (4e). Repeated column chromatography of fraction 2 followed by crystallization from $i-\mathrm{PrOH}$ and petroleum ether afforded pure $4 \mathbf{e}(0.3 \mathrm{~g}, 15 \%)$ as colorless crystals; mp 102-103 ${ }^{\circ} \mathrm{C} .{ }^{1} \mathrm{H}$ NMR: $\delta 2.53(3 \mathrm{H}, \mathrm{s}, \mathrm{Me}), 3.89(3 \mathrm{H}, \mathrm{s}, \mathrm{MeO}), 6.98(2 \mathrm{H}$, m, $m-\mathrm{H}), 7.89(2 \mathrm{H}, \mathrm{m}, o-\mathrm{H}), 7.98(1 \mathrm{H}, \mathrm{d}, 3-\mathrm{H}), 8.30(1 \mathrm{H}, \mathrm{d}, 5-\mathrm{H})$. Anal. Calcd. for $\mathrm{C}_{14} \mathrm{H}_{12} \mathrm{O}_{3} \mathrm{~S}: \mathrm{C}$, 64.60; H, 4.65; S, 12.32. Found: C, 65.13; H, 4.87; S, 11.56.

4-Acetyl-2-(4-hydroxybenzoyl)thiophene (4d). Fraction 3, colorless crystals $\left(\mathrm{mp} 150{ }^{\circ} \mathrm{C}\right)$ was contaminated ( ${ }^{1} \mathrm{H}$ NMR) with ca $8 \%$ of diketone 4e. 4d: ${ }^{1} \mathrm{H}$ NMR: $\delta: 2.58(3 \mathrm{H}, \mathrm{s}, \mathrm{Me}), 1.25(1 \mathrm{H}$, br s, HO), $6.96(2 \mathrm{H}, \mathrm{m}, m-\mathrm{H}), 7.86(2 \mathrm{H}, \mathrm{m}, o-\mathrm{H}), 7.92(1 \mathrm{H}, \mathrm{d}, 3-\mathrm{H}), 8.35(1 \mathrm{H}, \mathrm{d}, 5-\mathrm{H})$. The IR of this fraction exhibits a strong broad band at $3300\left(v_{\mathrm{OH}}\right)$ and a narrow band at $1670 \mathrm{~cm}^{-1}\left(v_{\mathrm{CO}}\right)$.

\section{References}

1. Belen'kii, L. I. Izv. Akad. Nauk SSSR, Ser. Khim. 1975, 344 (English translation: Bull. Acad. Sci. USSR. Div. Chem. Sci. 1975, 24, No. 2); Chem. Abstr. 1975, 82, 138644.

2. Belen'kii, L. I. In Novye napravleniya khimii tiofena (New Trends in Thiophene Chemistry), Gol'dfarb, Ya. L. Ed., Nauka: Moscow, 1976, Chapt. 1.

3. Gol'dfarb, Ya. L.; Yakubov, A. P.; Belen'kii, L. I. Dokl. Akad. Nauk SSSR (Rep. USSR Acad. Sci.) 1969, 185, 91; Chem. Abstr. 1969, 70, 114911.

4. Yakubov, A. P.; Belen'kii, L. I.; Gol'dfarb, Ya. L. Zh. Org. Khim. 1973, 9, 1959 (English translation: USSR J. Org. Chem. 1973, 9); Chem. Abstr. 1974, 80, 14801.

5. Belen'kii, L. I.; Gromova, G. P.; Kolotaev, A. V.; Krayushkin, M. M. Khim Geterotsikl. Soed. 2000, 315 (English translation: Chem. Heterocycl. Compds. 2000, 36, No. 3, 256).

6. Belen'kii, L. I.; Brokhovetsky, D. B.; Krayushkin, M. M. Chem. Scripta, 1989, $29,81$.

7. Yagupol'skii, L. M.; Pavlenko, N. G.; Solodushenkov, S. N.; Fialkov, Yu. A. Ukr. Khim. Zhurn. 1966, 32, 849; Chem. Abstr. 1966, 65, 107747.

8. Promyshlennye khlororganicheskie producty. Spravochnik, Oshin, L. A. Ed. (Industrial Organochlorine Products. Handbook), Khimiya, Moscow, 1978, pp. 478, 480. 